\title{
In vitro and in vivo anti-malarial activity of novel harmine-analog heat shock protein 90 inhibitors: a possible partner for artemisinin
}

\author{
Abebe Genetu Bayih ${ }^{1,2^{*}}$, Asongna Folefoc ${ }^{1}$, Abu Naser Mohon' ${ }^{1}$ Scott Eagon ${ }^{3}$, Marc Anderson ${ }^{4}$ \\ and Dylan R. Pillai ${ }^{1}$
}

\begin{abstract}
Background: The emergence of artemisinin-resistant Plasmodium falciparum strains poses a serious challenge to the control of malaria. This necessitates the development of new anti-malarial drugs. Previous studies have shown that the natural beta-carboline alkaloid harmine is a promising anti-malarial agent targeting the $P$. falciparum heat-shock protein 90 (PfHsp90). The aim of this study was to test the anti-malarial activity of harmine analogues.
\end{abstract}

Methods: Forty-two harmine analogues were synthesized and the binding of these analogues to P. falciparum heat shock protein 90 was investigated. The in vitro anti-malarial activity of two of the analogues, $17 \mathrm{~A}$ and $21 \mathrm{~A}$, was evaluated using a 72-h growth inhibition assay. The in vivo anti-malarial activity was tested in Plasmodium berghei infection of BALB/c mice. The potential of $21 \mathrm{~A}$ for a combination treatment with artemisinin was evaluated using in vivo combination study with dihydro-artemisinin in BALB/c mice. Cytotoxicity of the harmine analogues was tested in vitro using HepG2 and HeLa cell lines.

Results: $17 \mathrm{~A}$ and $21 \mathrm{~A}$ bound to $\mathrm{PfH} s \mathrm{sp} 9$ with average $\mathrm{IC}_{50}$ values of $12.2 \pm 2.3$ and $23.1 \pm 8.8 \mu \mathrm{M}$, respectively. They also inhibited the P. falciparum W2 strain with average $I C_{50}$ values of $4.2 \pm 1.3$ and $5.7 \pm 1.7 \mu \mathrm{M}$, respectively. In vivo, three daily injections of $P$. berghei-infected BALB/C mice with $100 \mathrm{mg} / \mathrm{kg}$ of either $17 \mathrm{~A}$ or $21 \mathrm{~A}$ showed significant reduction in parasitaemia with a 51.5 and $56.1 \%$ reduction, respectively. Mice treated with $17 \mathrm{~A}$ and $21 \mathrm{~A}$ showed a median survival time of 11 and 14 days, respectively, while the vehicle control mice survived a median of only 8.5 days. A dose-ranging experiment with $21 \mathrm{~A}$ showed that the compound has a dose-dependent anti-malarial effect. Furthermore, treatment of infected mice with a combination of 21A and dihydroartemisinin (DHA) showed a dramatic reduction in parasitaemia compared to treatment with DHA alone.

Conclusion: A novel and non-toxic harmine analogue has been synthesized which binds to PfHsp90 protein, inhibits $P$. falciparum in vitro at micromolar concentration, reduces parasitaemia and prolongs survival of $P$. berghei-infected mice with an additive anti-malarial effect when combined with DHA.

Keywords: Malaria, Plasmodium falciparum, Anti-malarial drugs, Heat-shock protein 90

\section{Background}

Malaria is one of the leading causes of morbidity and mortality from infectious diseases. A recent report by World Health Organization (WHO) estimated that 3.2

\footnotetext{
*Correspondence: abebegenetu@gmail.com; agbayih@ucalgary.ca ${ }^{2}$ Department of Medical Parasitology, College of Medicine and Health Sciences, University of Gondar, Gondar, Ethiopia
}

Full list of author information is available at the end of the article billion people are at risk of contracting the disease. In 2015 alone, there were an estimated 214 million cases of malaria worldwide with 438,000 deaths. Ninety per cent of the deaths occurred in WHO African Region where children are the main victims [1].

Multidimensional intervention in malaria control over the last decade has significantly reduced the incidence and mortality caused by malaria worldwide. These include the provision of insecticide-treated bed 
nets, indoor residual spraying, rapid diagnostic tests, and a supply of effective artemisinin-based combination therapy (ACT). As a result, many countries have initiated malaria elimination programmes. However, the emergence of Plasmodium falciparum strains that are resistant to artemisinin in Southeast Asian countries is posing a huge challenge to future malaria control and elimination efforts. The possibility of dissemination of the resistant strains to Africa is projected to have potentially catastrophic outcomes [1]. This calls for the urgent search for new and effective anti-malarial drugs.

Currently, ACT is the most widely used treatment for uncomplicated malaria. Since artemisinin is a fast-acting drug with a short half-life, it should be combined with another drug with longer half-life in order to effectively clear the parasite and prevent the emergence of drugresistant strains. Several partner drugs have been used as a component of ACT. Unfortunately, treatment failures in the partner drugs have emerged, threatening to curb the positive achievements gained to date in the fight against malaria and exposing artemisinin [2-4]. This necessitates the development of new partner drugs to use in ACT in places where resistance to artemisinin has not developed.

Heat shock proteins (Hsps) are the major chaperone proteins found in all life forms, ranging from prokaryotes to higher organisms, such as plants and mammals. Hsps are both constitutive and stress-inducible [5, 6]. Environmental factors, such as an abrupt change in temperature, upregulates the expression of Hsps [7, 8].

The life cycle of parasites such as Plasmodium, Leishmania and Trypanosoma involves poikilothermic insect vectors and homoeothermic mammalian hosts. These parasites are exposed to a sudden change in temperature of up to $10{ }^{\circ} \mathrm{C}$ during the transition from the insect-stage to mammalian-stage of the parasites, and have evolutionarily developed molecular chaperones to withstand the drastic change in temperature $[9,10]$ : for example, about $2 \%$ of the genes of $P$. falciparum code for proteins that serve as molecular chaperones [9]. Su and Wellems [11] showed that transcription of $P$. falciparum heat shock protein 90 (PfHsp90) increases up to three- and four-fold as a result of in vitro cultivation of the parasite at 39 and $41^{\circ} \mathrm{C}$, respectively.

Depending on their molecular size, Hsps are classified as small heat shock proteins (sHsps), Hsp40, Hsp60, Hsp70, Hsp90, and Hsp110. Hsp90 is one of the most abundant cytosolic proteins of a eukaryotic cell. The $\mathrm{N}$-terminal domain of $\mathrm{Hsp} 90$ has an ATP binding pocket responsible for its ATPase activity [12, 13]. Hsps play a crucial role in the normal metabolic activities of cells. By facilitating the proper folding of proteins, Hsps are involved in intracellular protein trafficking, gene expression, cell cycle, as well as cell differentiation $[5,9,14]$.
The crucial role of Hsp90 in chaperoning several important cellular functions and the structural differences in the ATP-binding domain of human and parasite Hsp90 make it a potentially viable drug target against several parasitic infectious diseases $[15,16]$. Molecular characterization of the $\mathrm{PfHsp} 90$ protein from clinical isolates of $P$. falciparum collected from patients in diverse geographical regions has shown that the ATPbinding domain of PfHsp90 is highly conserved among the isolates [17] thus reducing the likelihood of resistance emerging. Hsp90 is an essential protein in eukaryotic systems and not compatible with viability if knocked out. That is, mutations in the ATP binding domain of PfHsp90 make the protein inactive, negatively affecting important biological functions and incur the parasite too much fitness cost [18-20]. Interestingly, it has been shown that PfHsp90 may be associated with a P. falciparum chloroquine resistance transporter (PfCRT) protein from a chloroquine-resistant parasite strain. Immunoprecipitation experiments showed that PfHsp90 complex coimmunoprecipitated with PfCRT from $P$. falciparum W2 strain. Moreover, the use of a PfHsp90 inhibitor, PU-H71, resulted in loss of PfCRT protein [21]. It is postulated that targeting PfHsp90 in chloroquine-resistant $P$. falciparum strain could reverse the resistance and render the parasite chloroquine sensitive again. This effect may not be restricted to a single drug class given the broad range of chaperone activity that Hsp90 regulates.

The discovery of the natural compound, geldanamycin opened a new avenue in the development of drugs targeting Hsp90. Geldanamycin has displayed a strong anticancer and anti-malarial effect in vitro. However, a strong hepatotoxic signal precludes its clinical use. As a result, different derivatives of geldanamycin have been developed that have an acceptable level of hepatotoxicity [22]. In vitro and in vivo experiments have shown that the geldanamycin-derivatives, 17AAG and 17-PEG-AlkynGA, are promising anti-malarial compounds targeting PfHsp90 [23, 24].

In addition to geldanamycin and its derivatives, other small molecules such as purine analogues have been found to effectively inhibit Hsp90 in vitro and in vivo. One such molecule is PU-H71. This molecule has been tested as an anti-cancer drug [25]. Recently, it has been demonstrated that PU-H71 has a good anti-malarial activity in vitro and in mice [21]. Harmine, a beta carboline alkaloid, is able to selectively bind PfHsp90 to a greater extent than human Hsp90 (HsHsp90) [26]. Harmine has been reported as having a specific highaffinity interaction with the ATP-binding domain of PfHsp90 with strong inhibition of $P$. falciparum in cell culture systems. In the P. berghei ANKA infection model in mice, harmine showed a significant reduction in 
parasitaemia. However, it did not significantly prolong the survival of the infected mice $[17,26]$.

In this study, a library of harmine analogues were generated and their ability to bind PfHsp90, inhibit $P$. falciparum in culture, and kill parasites in the P. berghei infection mice model was tested. It was hypothesized that the harmine analogues have a strong anti-malarial effect both in vitro and in vivo in mice. It has been found that some of the harmine analogues effectively bind to PfHsp90, inhibit the growth of P. falciparum in vitro, significantly reduce parasitaemia in infected $B A L B / c$ mice in a dose-dependent manner, and prolong the survival of infected mice. Interestingly, two daily injections with a combination of $100 \mathrm{mg} / \mathrm{kg}$ of $21 \mathrm{~A}$ (one of the harmine analogues) and $10 \mathrm{mg} / \mathrm{kg}$ dihydro-artemisinin (DHA) was able to reduce parasitaemia to an undetectable level in infected mice.

\section{Methods}

\section{Synthesis of harmine analogues}

Forty-two different analogues of harmine were generated using a microwave-assisted synthetic route, as described previously [27]. Based on the results of the PfHsp90 binding assay, two out of 42 compounds were selected and tested for in vitro and in vivo anti-malarial activity. The chemical structures of harmine $17 \mathrm{~A}$ and $21 \mathrm{~A}$ are shown in Fig. 1.

\section{PfHsp90 competitive binding assay}

Binding of the harmine-derived compounds with the ATP-binding domain of PfHsp90 was assessed using a bis-ANS (4, 4'-Dianilino-1, 1'-binaphthyl-5, 5'-disulfonic acid dipotassium salt) binding assay $[28,29]$. The expression and purification of the PfHsp90 GHKL domain as

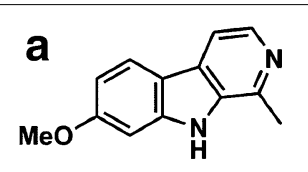

Harmine

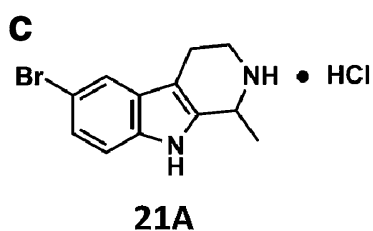

Fig. 1 The chemical structure of harmine analogues. Forty-two different analogues of harmine were generated using a microwaveassisted synthetic route. Two compounds were selected based on their binding to the ATP-binding domain of pfHsp90. a Harmine, $\mathbf{b}$ $17 \mathrm{~A}$ and $\mathbf{c} 21 \mathrm{~A}$ well as the bis-ANS assay was performed as previously described [17]. Briefly, the P. falciparum Hsp90 GHKL domain DNA was cloned into pET28b plasmid vector and the His-tagged protein was expressed in Escherischia coli BL21 (DE3) CondonPlus cells. The recombinant protein was purified using Ni-NTA resin and the His-tag was cleaved using TEV protease. The competitive binding assay was performed by mixing bis-ANS with the purified recombinant protein that was pre-incubated at $37^{\circ} \mathrm{C}$ in the presence or absence of the harmine analogues. The fluorescence emission was captured at $490 \mathrm{~nm}$.

\section{In vitro parasite culture and anti-malarial activity assay}

A 72-h in vitro growth inhibition assay was used to test the anti-malarial activity of the harmine analogues. Plasmodium falciparum line 3D7 (MRA-102), line W2 (MRA-157), as well as artemisinin-resistant $P$. falciparum strains (MRA-1236 and MRA-1240) were obtained from MR4 (MR4, ATCC ${ }^{\circledR}$ Manassas, Virginia, USA). Plasmodium falciparum was cultured in complete RPMI-1640 medium with $1.5 \%$ haematocrit and incubated in a $\mathrm{CO}_{2}$ enriched atmosphere. The parasite growth was synchronized by treating with $5 \%$ sorbitol and cultured for $48 \mathrm{~h}$. In vitro susceptibility of the parasite to the candidate drugs was performed using histidine rich protein (HRP)II ELISA [30, 31]. First, the drug plates were prepared in ten-fold serial dilution with a total of ten drug concentrations and one drug-free control in 96-well, flat-bottomed Costar $^{\circledR}$ tissue culture plate (Corning, USA) in duplicate. Two-hundred $\mu \mathrm{L}$ of the parasite culture with a parasitaemia of $0.05 \%$ and a haematocrit of $1.5 \%$ was added into each well with a known drug concentration. The drugtreated parasites were incubated at $37{ }^{\circ} \mathrm{C}$ in a candle jar for $72 \mathrm{~h}$. Then, the plates were kept in a $-20{ }^{\circ} \mathrm{C}$ freezer for at least $24 \mathrm{~h}$ before lysis of red blood cells was performed by two freeze-thaw cycles.

HRP-II ELISA was performed following the procedure in the Worldwide Antimalarial Resistance Network (WWARN) manual [32]. Briefly, a 96-well, high-binding ELISA plate $\left(\operatorname{Costar}^{\circledR}\right.$, Corning Inc, USA) was coated with $1.0 \mu \mathrm{g} / \mathrm{mL}$ anti-HRP-II IgM capture antibody (Immunology Consultants Laboratories, OR, USA) in PBS and incubated at $4{ }^{\circ} \mathrm{C}$ overnight. Next morning, the unbound antibody was removed by blotting on a paper towel and blocking was performed with $200 \mu \mathrm{L} /$ well of $2 \%$ bovine serum albumin (BSA) at room temperature for $2 \mathrm{~h}$. After removing the blocking buffer, the plate was washed twice with PBS containing $0.05 \%$ Tween ${ }^{\circledR} 20$ (Sigma, MO, USA). One-hundred $\mu \mathrm{L}$ of the sample was then added to each well, incubated at room temperature for $1 \mathrm{~h}$ and washed twice as above. Then, $100 \mu \mathrm{L} /$ well of a secondary anti-HRP-II antibody conjugated with horse radish peroxidase (Immunology Consultants Laboratories, OR, 
USA) diluted in $2 \%$ BSA $/ 1 \%$ Tween ${ }^{\circledR} 20$ in PBS was added and incubated for $1 \mathrm{~h}$ at room temperature. The plate was washed twice, and then $100 \mu \mathrm{L} /$ well of TMB chromogen (Invitrogen, CA, USA) was added and incubated for 2-10 min at room temperature in the dark. The reaction was then stopped by adding $50 \mu \mathrm{L}$ of $1 \mathrm{M}$ sulfuric acid to each well. Finally, the absorbance at $450 \mathrm{nM}$ was taken using a SpectraMax ${ }^{\circledR} 340$ ELISA plate reader (Molecular Devices, USA).

\section{In vivo anti-malarial assay in mice}

4- to 5-weeks old female BALB/c mice were purchased from Charles River Laboratories (QC, Canada). The mice were kept in a pathogen-free environment at the health science animal research facility of the University of Calgary, Canada. A review of existing mouse malaria models has been described previously [33]. After acclimatizing for one week, four- to five-weeks old female BALB/c mice were randomly distributed to experimental and control groups. Each group consisted of five mice. Plasmodium berghei ANKA (kindly provided by Dr Ian Crandall, University of Toronto, ON, Canada) was thawed at $37{ }^{\circ} \mathrm{C}$ water bath and injected aseptically into the donor mice intraperitoneally. Blood was collected by cardiac puncture when the parasitaemia reached $5-10 \%$. Then, $10^{6}$ parasite-infected red blood cells (RBCs) were injected interaperitoneally into each mouse in the experimental and control groups. After confirmation of parasiatemia, each mouse in the experimental groups was given intraperitoneal injection of the experimental compound(s) dissolved in $10 \%$ dimethyl sulfoxide (DMSO). Positive and negative control mice were injected with chloroquine and DMSO, respectively. For the combination experiment, 21A and DHA were prepared separately and mixed just before injection. The efficacy of the drugs was then assessed by determining the percentage of infected RBCs in Giemsa-stained blood collected by tail vein puncture daily. Survival of the drug-treated mice was compared with that of the controls. Mice that showed a net weight loss of more than $20 \%$ and with symptoms of severe malaria were euthanized.

\section{Cytotoxicity assay}

Cytotoxicity of the candidate drugs was tested on HepG2 and HeLa cell lines using Cell Counting Kit-8 (Sigma). Immortalized human cell lines such as HepG2 and HeLa cells have been used in previous studies to assess the cytotoxicity of several compounds including anti-malarial candidate drugs in vitro [34-36]. All the cell culture reagents were bought from Life Technologies (Canada). HepG2 cells were cultured in DMEM (low glucose) plus $10 \%$ FBS. HeLa cells were grown in DMEM (high glucose) plus 10\% FBS and $1 \mathrm{mM}$ Pyruvate.
A modification of the procedure used by RamirezMares et al. [37] was followed. Briefly, exponentially growing cells were trypsinized and suspended in fresh medium at a density of $5 \times 10^{4}$ cells $/ \mathrm{ml}$. One-hundred $\mu \mathrm{L}$ of the cell suspension was then dispensed into each well of a 96-well, flat-bottomed Costar ${ }^{\circledR}$ tissue culture plate (Corning, USA) in triplicate and pre-incubated for $24 \mathrm{~h}$ in a humidified incubator at $37{ }^{\circ} \mathrm{C}$ and $5 \% \mathrm{CO}_{2}$. Drug plates were prepared by serially diluting the drugs. Eight ten-fold dilutions of each drug were prepared starting at $5 \mathrm{mM}$. In addition to the candidate drugs, chloroquine, geldanamycin and DMSO were included as controls. Then, $10 \mu \mathrm{L} /$ well of various concentrations of the drugs was added into the cells. Drug-free cells were also included as a control. The cells were then incubated at $37{ }^{\circ} \mathrm{C}$ and $5 \% \mathrm{CO}_{2}$ for $48 \mathrm{~h}$. Then, $10 \mu \mathrm{L} /$ well of CCK-8 reagent was added and incubated at $37{ }^{\circ} \mathrm{C}$ for an additional $4 \mathrm{~h}$. Finally, the absorbance at $450 \mathrm{~nm}$ was measured using a SpectraMax ${ }^{\circledR} 340$ ELISA plate reader (Molecular Devices, USA). Wells containing only media were also included as a control.

\section{Statistical analysis}

The statistical differences in per cent parasitaemia inhibition between drug-treated and vehicle control mice were analysed using $t$ test. The log-rank (Mantel-Cox) test was done to analyse the statistical difference in the survival of drug-treated and control mice. A $p$ value of less than 0.05 was considered statistically significant. All statistical analyses were done using Graphpad Prism 6 software.

\section{Results}

\section{Harmine analogues bind to PfHsp90}

Of the 42 harmine analogues tested, two (17A and 21A) showed binding to the ATP-binding domain of PfHsp90. The average $\mathrm{IC}_{50}$ values for the binding of $17 \mathrm{~A}$ and $21 \mathrm{~A}$ with PfHsp90 were $12.2 \pm 2.3$ and $23.1 \pm 8.8 \mu \mathrm{M}$, respectively (Fig. 2). Unfortunately, 22 of the harmine analogues (the beta-carboline 'B' series of compounds) were not amenable to testing due to auto-fluorescence in the bisANS assay and were subsequently excluded from further study.

\section{Harmine analogues inhibit the growth of Plasmodium falciparum}

The in vitro anti-malarial efficacy of $17 \mathrm{~A}$ and $21 \mathrm{~A}$ was assessed against $P$. falciparum W2 using HRP-II ELISA in a whole cell assay. The average $\mathrm{IC}_{50}$ values were $4.2 \pm 1.3$ and $5.7 \pm 1.7 \mu \mathrm{M}$ for $17 \mathrm{~A}$ and $21 \mathrm{~A}$, respectively. The anti-malarial activity of $21 \mathrm{~A}$ was also measured against artemisinin-resistant strains. It showed growth inhibition of MRA-1236 and MRA-1240 strains with average $\mathrm{IC}_{50}$ values of $9.2 \pm 0.4$ and $9.6 \pm 2.0 \mu \mathrm{M}$, respectively. 

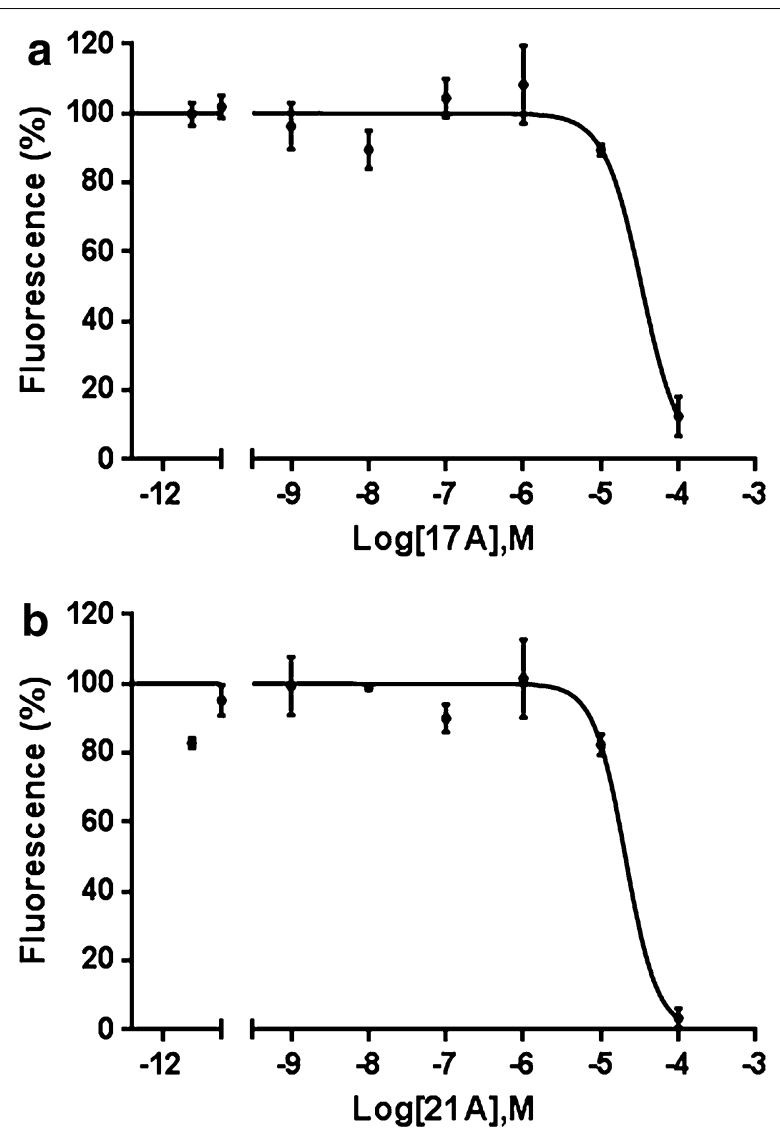

Fig. 2 Normalized dose-response curve for the competitive binding assay. Binding of (a) 17A and (b) 21A to the ATP binding domain of PfHsp90 was assessed using the bis-ANS competitive binding assay. Reduction in the fluorescence of bis-ANS was measured using a spectrophotometer. The average $I C_{50}$ values were calculated from three experiments using Graphpad Prism 6. The mean fluorescence and standard error of the mean (SEM) of duplicate wells is shown. Each graph is a representative of three independent experiments

Interestingly, 21A showed comparatively lower activity against chloroquine and artemisinin-sensitive $P$. falciparum 3D7 strain with average $\mathrm{IC}_{50}$ value of $13.5 \pm 0.8 \mu \mathrm{M}$ (Fig. 3).

\section{Harmine analogues significantly reduce parasitaemia in infected mice and prolong their survival}

The in vivo efficacy of the harmine analogue compounds was tested using P. berghei ANKA infection in BALB/c mice. For the fixed-dose experiment, the drug treatment was started at day-4 post-infection with a starting average parasitaemia of about $3.5 \%$. Three daily injections of infected mice with $100 \mathrm{mg} / \mathrm{kg}$ of each of $17 \mathrm{~A}$ and $21 \mathrm{~A}$ showed statistically significant reduction in parasitaemia compared to the vehicle control $(\mathrm{p}<0.05)$. At day-7 post-infection (i.e., one day after the last dose of the drugs), $17 \mathrm{~A}$ and $21 \mathrm{~A}$ resulted in reduction of parasitaemia by 51.5 and $56.1 \%$, respectively (Fig. $4 a$ ). The positive control mice that received a daily injection of $30 \mathrm{mg} / \mathrm{kg}$ chloroquine for three consecutive days cleared the infection to microscopically undetectable levels and remained so until the end of the experiment. Figure $4 \mathrm{~b}$ shows the Kaplan-Meier survival curve of the mice treated with the candidate drugs and controls. Mice treated with $17 \mathrm{~A}$ and $21 \mathrm{~A}$ showed a median survival time of 11 and 14 days, respectively, while the vehicle control mice showed a median survival time of only 8.5 days. Log-rank (Mantel-Cox) test indicated that the survival of mice treated with $21 \mathrm{~A}$ was significantly higher than vehicle control mice $(\mathrm{p}<0.05)$. Of the two hamine-analogues tested for in vivo anti-malarial activity at a fixed dose, 21A was selected for a dose-ranging experiment. Four different doses of $21 \mathrm{~A}$ were used for the dose-ranging experiment; 100, 75, 50 and $25 \mathrm{mg} /$ $\mathrm{kg}$. Chloroquine and DMSO were used as a positive and vehicle controls, respectively. Five female BALB/c mice were used in each group. The degree of parasitaemia and survival rate in infected mice showed that $21 \mathrm{~A}$ has antimalarial activity in a dose-dependent manner. One day after administration of the third dose, mice treated with 100,75 and $50 \mathrm{mg} / \mathrm{kg}$ demonstrated a significantly lower parasitaemia than the mice in the vehicle control group ( $\mathrm{p}<0.05)$ (Fig. 5a). The per cent parasitaemia reduction in these groups was $48.1,37.5$ and $27.2 \%$, respectively. Like in the fixed-dose experiment, mice that were treated with chloroquine cleared the infection to microscopically undetectable levels. Comparison of drugtreated mice with the vehicle control ones indicated that at doses of $50 \mathrm{mg} / \mathrm{kg}$ and above, the survival of drugtreated mice increased significantly than the controls $(\mathrm{p}<0.05)$ (Fig. 5b).

\section{A has additive effect with dihydro-artemisinin}

In order to investigate the potential of $21 \mathrm{~A}$ to be used as a partner drug with artemisinin in a combination therapy model, the anti-malarial efficacy of a combination of 21A and DHA was tested and compared-with the efficacy of the individual drugs alone. The data show that treatment with a combination of $100 \mathrm{mg} / \mathrm{kg}$ $21 \mathrm{~A}$ and $10 \mathrm{mg} / \mathrm{kg}$ DHA results in a more potent antimalarial activity than treatment with DHA alone. Figure $6 \mathrm{a}$ shows the per cent parasitaemia inhibition of treatment with a combination of $21 \mathrm{~A}$ and DHA or with individual drugs alone. One day after administration of two doses of the combined drugs, all five mice $(100 \%)$ cleared the infection with undetectable parasitaemia by microscopy. In contrast, only $40 \%$ (two out of five) of the mice treated with DHA alone cleared the infection at this time point. No mouse treated with $21 \mathrm{~A}$ alone achieved undetectable parasitaemia. One day after the 

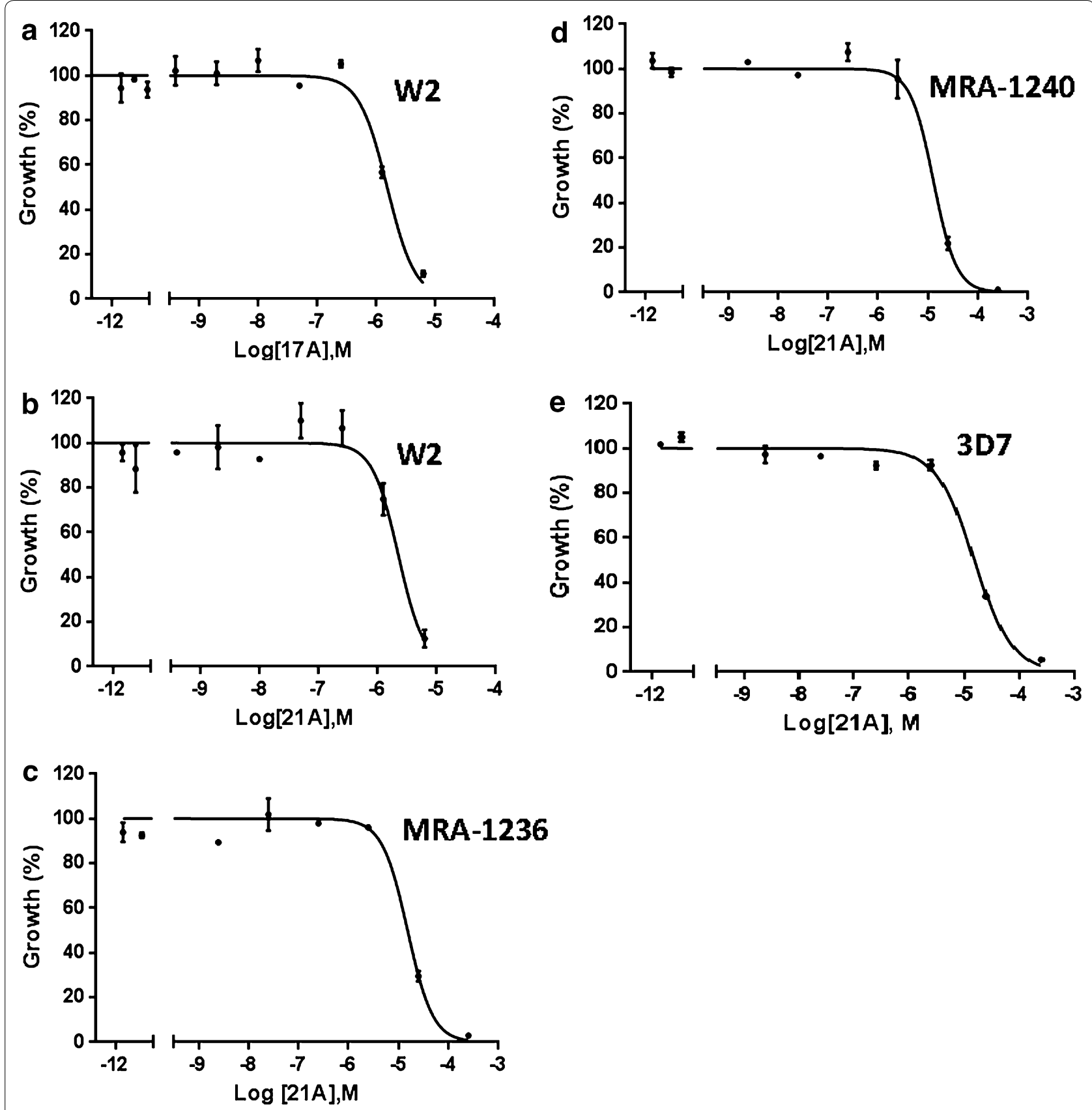

Fig. 3 Normalized dose-response curve for the in vitro susceptibility of Plasmodium falciparum to $17 \mathrm{~A}$ and $21 \mathrm{~A}$. The in vitro anti-malarial effect of $17 \mathrm{~A}$ and $21 \mathrm{~A}$ was measured using HRP-II ELISA of drug treated P. falciparum strains. a 17A against W2, b 21A against W2, c 21A against MRA-1236, d 21 A against MRA-1240, and $\mathbf{e} 21 \mathrm{~A}$ against 3D7. IC 50 values were calculated from the dose-response curve using Graphpad Prism 6. The experiment was performed in duplicate wells. The mean OD $450 \mathrm{~nm}$ and the standard error of the mean (SEM) of duplicate wells and is shown. Each graph is a representative of three independent experiments

last dose of treatment, 100 and $60 \%$ of the mice that received the combination and DHA alone had undetectable parasitaemia, respectively (Fig. 6a). However, the mice that received the combination developed microscopically detectable parasitaemia at later time points. Likewise, the mice treated with a combination of $21 \mathrm{~A}$ and DHA survived longer than those that were treated with either $21 \mathrm{~A}$ or DHA alone. Two mice survived until the end of the experiment (day-16) and were sacrificed (Fig. 6b). 

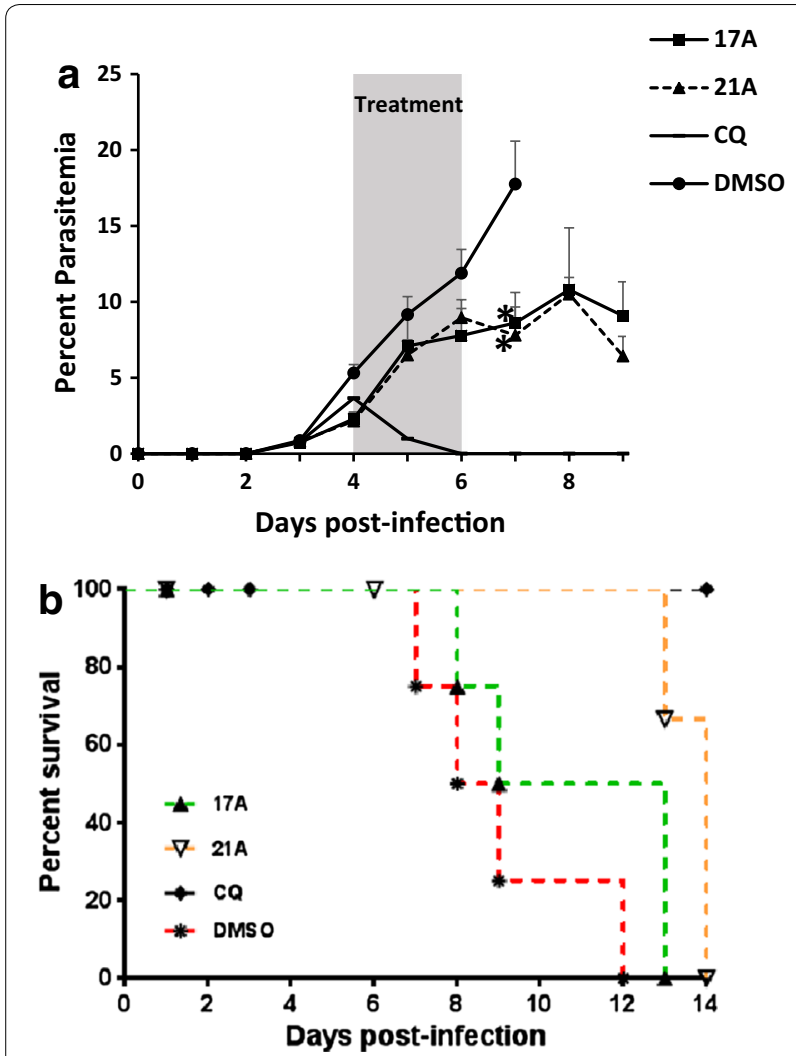

Fig. 4 Parasitaemia inhibition and survival of mice treated with a fixed dose of harmine-analogues. Five BALB/c mice per group were infected with $P$. berghei ANKA. The mice were treated with three daily doses of $100 \mathrm{mg} / \mathrm{kg}$ of $17 \mathrm{~A}$ or $21 \mathrm{~A}$ starting at day-4 post infection. The positive and negative control mice were given three daily doses of $100 \mathrm{mg} / \mathrm{kg}$ chloroquine and 10\% DMSO, respectively. a Per cent parasitaemia. The graph is the mean parasitaemia and standard error of the mean (SEM) of five mice in a group, and $\mathbf{b}$ Kaplan-Meier survival plot of mice treated with the harmine analogues and controls. Asterisk indicates a statistically significant difference between the drug treated mice and the vehicle control group (DMSO)

\section{A and $21 A$ are not toxic to HepG2 and HeLa cells}

To investigate the possibility of toxicity in human host, the cytotoxicity of the compounds was tested in vitro in HepG2 and HeLa cells. The result showed that 17A and 21A are not toxic to either cell line. In HepG2 cells, the $\mathrm{IC}_{50}$ values of $17 \mathrm{~A}$ and $21 \mathrm{~A}$ were $0.16 \pm 0.01$ and $0.140 \pm 0.001 \mathrm{mM}$, respectively. On the other hand, in HeLa cells, 17A and $21 \mathrm{~A}$ had $\mathrm{IC}_{50}$ values of $1.1 \pm 0.3,0.48 \pm 0.14 \mathrm{mM}$, respectively (Fig. 7). Since it has proven hepatotoxicity, geldanamycin was also included as a control. As expected, it showed high degree of toxicity in HepG2 cells with $\mathrm{IC}_{50}$ in micromolar range $(0.34 \pm 0.13 \mu \mathrm{M})$.

\section{Discussion}

Heat shock proteins are crucial molecular chaperones that are involved in various central metabolic activities of both prokaryotic and eukaryotic cells. Because Hsps are
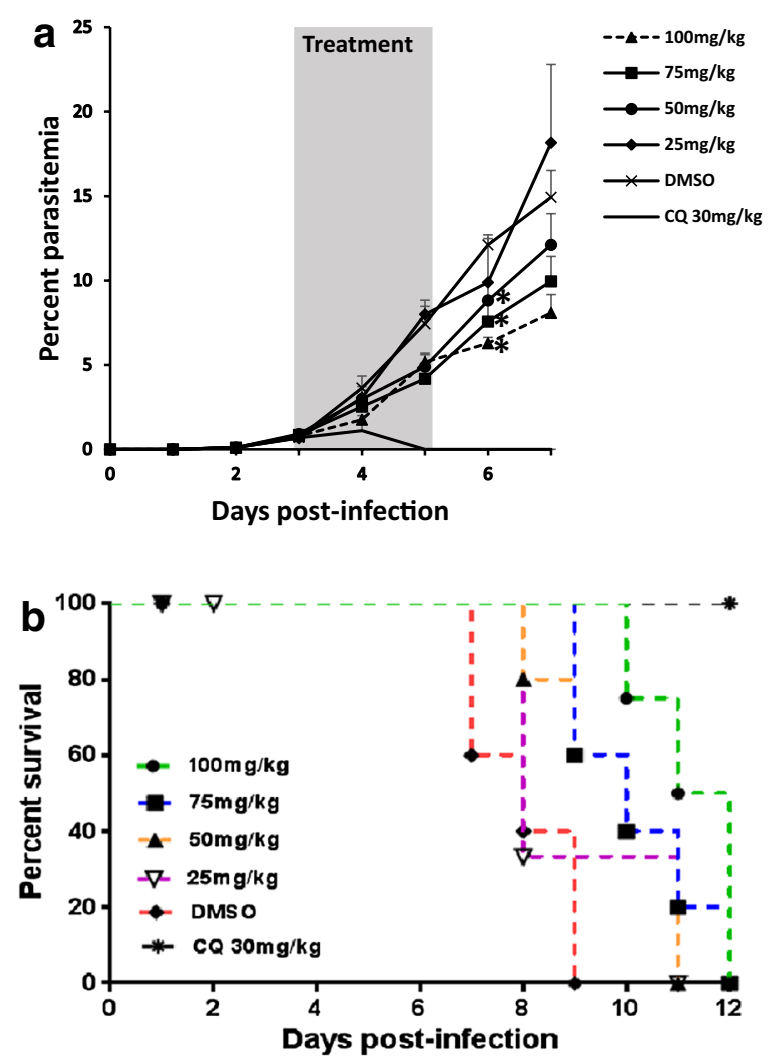

Fig. 5 Parasitaemia inhibition and survival of mice treated with different doses of $21 \mathrm{~A}$. Five BALB/c mice per group were infected with $P$. berghei ANKA. The mice were treated with three daily doses of $100,75,50$ or $25 \mathrm{mg} / \mathrm{kg}$ of $21 \mathrm{~A}$ starting at day-3 post infection. The positive and negative control mice were given three daily doses of $30 \mathrm{mg} / \mathrm{kg}$ chloroquine and 10\% DMSO, respectively. a Per cent parasitaemia. The graph is the mean parasitaemia and standard error of the mean (SEM) of five mice in a group, and $\mathbf{b}$ Kaplan-Meier survival plot of mice treated with different doses of $21 \mathrm{~A}$ and controls. Asterisk indicates a statistically significant difference between the drug treated mice and the vehicle control group (DMSO)

necessary for normal metabolic activities of a cell and to protect cells from stress conditions, they are conserved in all life forms. Although they are constitutively expressed, the level of expression of Hsps increases when challenged by stressors such as heat or $\mathrm{pH}$ changes. Hsp90's crucial role as an essential chaperone, association with resistance, and high degree of conservation make it an attractive adjunctive drug target [18, 19, 38, 39].

As a parasite with a life cycle involving poikilothermic insects and homoeothermic humans, P. falciparum has to adapt to the drastic change in temperature during transmission from the insect vector to human host. Plasmodium falciparum Hsp90 protein is the most abundant cytosolic protein and plays an indispensable role in resisting the effect of temperature change that occurs during transmission from insect vectors to humans. 

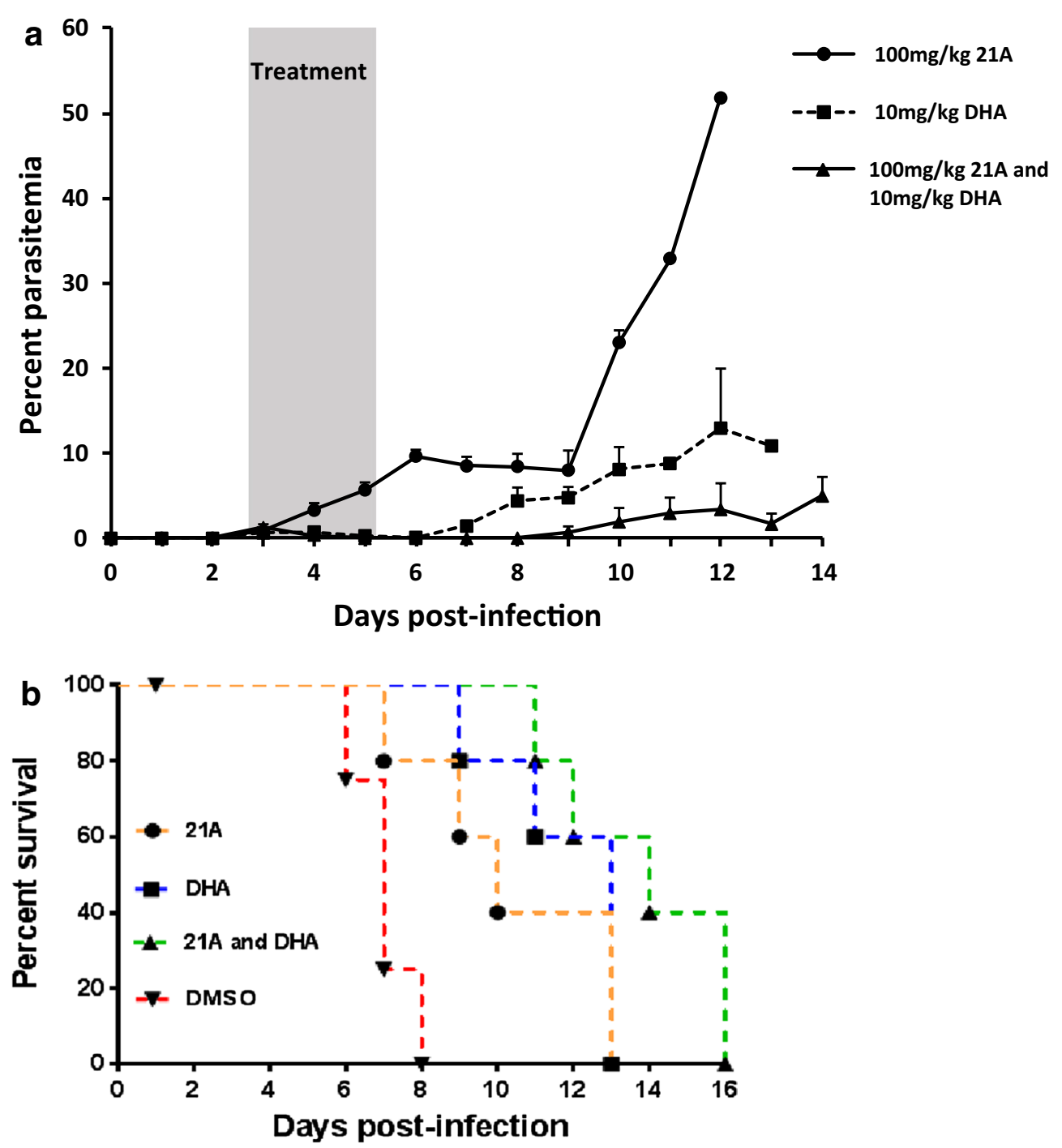

Fig. 6 Parasitaemia inhibition and survival of mice treated with a combination of 21A and dihydro-artemisinin. Five BALB/c mice per group were infected with P. berghei ANKA. The mice were treated with three daily doses of $100 \mathrm{mg} / \mathrm{kg} 21 \mathrm{~A}, 10 \mathrm{mg} / \mathrm{kg} \mathrm{DHA}$, a combination of $100 \mathrm{mg} / \mathrm{kg} 21 \mathrm{~A}$ and $10 \mathrm{mg} / \mathrm{kg}$ DHA starting at day-3 post infection. The negative control mice were given three doses of 10\% DMSO. a Per cent parasitaemia. The graph is the mean parasitaemia and standard error of the mean (SEM) of five mice in a group, and $\mathbf{b}$ Kaplan-Meier survival plot of mice treated with $21 \mathrm{~A}, \mathrm{DHA}$, and a combination of $21 \mathrm{~A}$ and $\mathrm{DHA}$

The ATPase activity of Hsp90 is a necessary precursor to its function and interaction with client proteins. Therefore, targeting the Hsp90 ATP-binding using a small molecule is expected to inhibit its chaperoning activity and render the client proteins to degradation via the cytosolic proteasome, which consequently inhibit major metabolic activities of the cell [40]. Several studies have tested the use of small molecules that bind to and competitively inhibit the ATPase activity of Hsp90 as candidate drugs for different infectious diseases and cancer [23, 41, 42]. Although the Hsp90 in humans and the malaria parasite have a high degree of homology, there are subtle and potentially significant structural differences that can be exploited when designing selective small-molecule inhibitors [16]. Moreover, cells from different organisms show variable degree of dependency on chaperone-supported metabolic activities. As a result, it is hypothesized that it is possible to inhibit the activity of Hsp of a pathogen without significant deleterious effects on the Hsps of the host $[5,17]$. It has been shown previously that natural compounds such as harmine and the ATP mimetic PU-H71 exert anti-Plasmodium activity by targeting PfHsp90 [21, 26]. In this study, 42 different derivatives of harmine were synthesized and the in vitro 

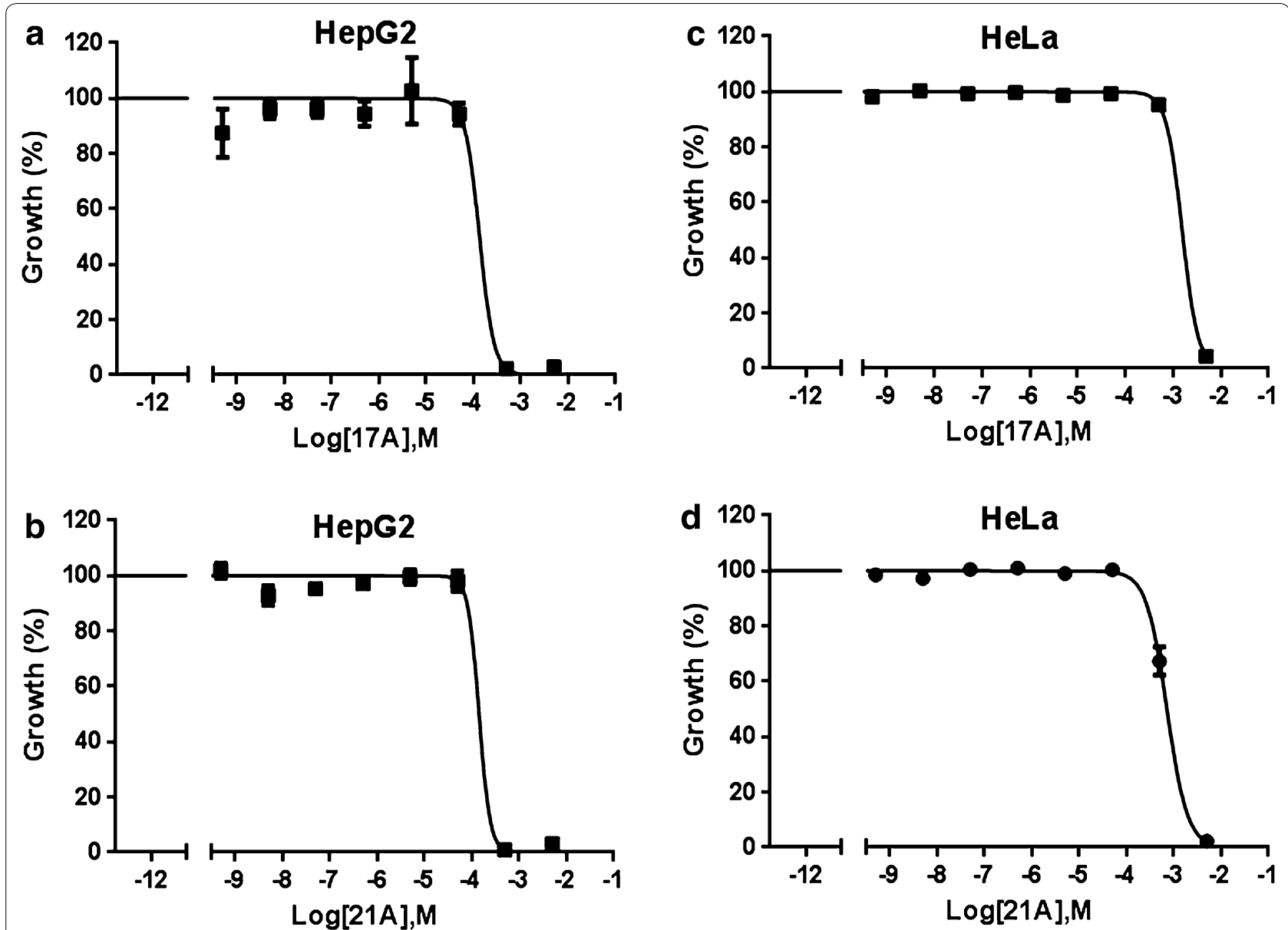

Fig. 7 Normalized dose-response curve for in vitro cytotoxicity of 17A and 21A. Human cell lines were cultured in the presence of 17A and 21A. Cytotoxicity of the compounds was evaluated using the CCK-8 kit. Per cent cell death was measured by measuring absorbance at OD $450 \mathrm{~nm}$. a HepG2 cells treated with 17A, b HepG2 cells treated with 21A, c HeLa cells treated with 17A, and d HeLa cells treated with 21A. The mean OD $450 \mathrm{~nm}$ and the standard error of the mean (SEM) of triplicate wells and is shown. Each graph is representative of three independent experiments

and in vivo anti-malarial activities of two of the harmine analogues was tested as single agents and in combination with artemisinin. Unfortunately, 22 harmine analogues displayed auto-fluorescence in bis-ANS assay and were consequently excluded from the study.

Two out of the remaining 20 compounds (17A and 21A) effectively bind to the ATP-binding domain of PfHsp90 with $\mathrm{IC}_{50}$ value in the low micromolar range. The $\mathrm{IC}_{50}$ values of $17 \mathrm{~A}$ and $21 \mathrm{~A}$ was comparable to that of radicicol, a compound that has been shown to tightly bind Hsp90 [43].

In vitro susceptibility of $21 \mathrm{~A}$ showed that the compound has anti-malarial activity against both chloroquine- and artemisinin-resistant $P$. falciparum strains with micromolar $\mathrm{IC}_{50}$ value. Generally, the chloroquineor artemisinin-resistant strains seem more susceptible to $21 \mathrm{~A}$ than the chloroquine-sensitive 3D7 strain. Similar effect was seen in the previous study with harmine.
That is, chloroquine-resistant W2 strain was almost twice more susceptible to harmine than chloroquinesensitive 3D7 strain [17]. It remains to be seen if inhibition of PfHsp90 in chloroquine-resistant strains affects other metabolic activities of the parasite in addition to reversing the resistance trait. The effect of inhibition of PfHsp90 activity on proteins associated with chloroquine- or artemisinin-resistance needs further study.

At a fixed dose of $100 \mathrm{mg} / \mathrm{kg}$ administered daily for three consecutive days, both $17 \mathrm{~A}$ and $21 \mathrm{~A}$ showed a significant parasitaemia reduction. Unlike $17 \mathrm{~A}$, treatment with $21 \mathrm{~A}$ significantly prolonged the survival time of treated mice. This property was not seen with the parent molecule harmine [26]. Therefore, 21A was selected for the dose-ranging and combination experiments. $21 \mathrm{~A}$ showed a dose-dependent activity with the highest parasitaemia reduction at a dose of $100 \mathrm{mg} / \mathrm{kg}$ followed by 75 and $50 \mathrm{mg} / \mathrm{kg}$. One day after the last dose of 
treatment, the group treated with $25 \mathrm{mg} / \mathrm{kg}$ did not show significant difference from the vehicle control. Interestingly, 21A showed an additive effect with DHA in vivo in mice. Treatment with a combination of $100 \mathrm{mg} / \mathrm{kg} \mathrm{21A}$ and $10 \mathrm{mg} / \mathrm{kg}$ DHA resulted in a dramatic reduction of parasitaemia to undetectable levels by microscopy on Giemsa-stained peripheral blood in just two doses. This stands in stark contrast with the result from mice that were treated with DHA alone where only two out of five mice cleared the infection. As such, 21A has promising potential as a partner drug with artemisinin either in combination or co-formulation. This is in line with previous studies that showed the possibility of using Hsp90 inhibitors as adjunctive drugs with the current antimalarial drugs [39]. Of note, it is not possible to determine if the combined effect in mice was due to synergy or an alternative effect. Because the parasitaemia in the combination treatment groups was reduced to undetectable levels by microscopy, it was not possible to calculate whether 21A has synergistic effect with DHA in vivo. FACS analysis of DNA-stained RBCs could have been an alternative approach to determine the parasite load in such conditions. However, FACS analysis was not performed due to lack of the required laboratory facility. On the other hand, pharmacokinetic analysis of $21 \mathrm{~A}$ and DHA in mice was not performed in this study. Pharmacokinetic and drug-drug interaction study between 21A and DHA is warranted to better understand the synergy.

In this study, differences were seen in the parasitaemia of mice that were treated with the same amount of $21 \mathrm{~A}$ in different experiments. This could be probably due to differences in experimental conditions. One such factor is the difference in the initial parasitaemia before drug administration.

In order to be considered as an effective candidate drug, a compound should not be toxic to the human host. The first step in evaluating toxicity is to investigate the cytotoxicity in cell lines in vitro. In this regard, the cytotoxicity of $17 \mathrm{~A}$ and $21 \mathrm{~A}$ was tested in HepG2 and HeLa cells in vitro. Comparing the $\mathrm{IC}_{50}$ value for the cytotoxicity with that of in vitro anti-malarial activity, in HepG2 cells, 17A and 21A had a favourable cytotoxicity selectivity index (SI) of 38 and 25, respectively. In HeLa cells, $17 \mathrm{~A}$ and 21A had an SI of 259 and 84, respectively. Future studies require the pursuit of a second generation library based on the current data which probably will yield compounds with increased potency against malaria in all stages of the life cycle.

\section{Conclusion}

The emergence of $P$. falciparum strains that are resistant to artemisinin or to the partner drugs in ACT poses a serious challenge to the current malaria elimination agenda.
This calls for the development of new 'smart' drugs that could be used as partner drugs with artemisinin. It has been previously shown that $P$. falciparum Hsp90 is highly conserved and performs a fundamental chaperone role in the cell. Harmine analogues that inhibit PfHsp90 have been developed and their anti-malarial activity tested in vitro and in vivo in mice. Two harmine analogues, $17 \mathrm{~A}$ and $21 \mathrm{~A}$, showed in vitro anti-malarial activity with micromolar range $\mathrm{IC}_{50}$ values. The analogues also showed in vivo anti-malarial activity with significant parasitaemia reduction in infected $\mathrm{BALB} / \mathrm{c}$ mice and increased survival. More importantly, 21A showed additive effects when used in combination with DHA, indicating that $21 \mathrm{~A}$ could be potentially used as a partner drug candidate. Future study on the pharmacokinetics of $21 \mathrm{~A}$ and also drug-drug interaction with DHA would be of great importance.

\section{Abbreviations}

PfHsp90: Plasmodium falciparum heat-shock protein 90; ACT: artemisininbased combination therapy; DHA: dihydro-artemisinin; PfCRT: Plasmodium falciparum chloroquine resistance transporter; BSA: bovine serum albumin; HRP-II: histidine-rich-protein-II; PBS: phosphate buffered saline; DMSO: dimethyl sulfoxide; ELISA: enzyme-linked immunosorbent assay.

\section{Authors' contributions}

$A G B, A F$ and DRP conceived and designed the study. SE and MA participated in the design of the study and synthesized the harmine analogues. AGB, AF and $A N M$ conducted the in vitro and animal experiments. AGB, AF and DRP analysed the data. AGB and DRP wrote the manuscript. All authors read and approved the final manuscript.

\section{Author details \\ ${ }^{1}$ Department of Pathology and Laboratory Medicine, MIID and Medicine, University of Calgary, Calgary, AB, Canada. ${ }^{2}$ Department of Medical Parasitol- ogy, College of Medicine and Health Sciences, University of Gondar, Gondar, Ethiopia. ${ }^{3}$ Department of Chemistry and Biochemistry, California Polytechnic State University, San Luis Obispo, CA, USA. ${ }^{4}$ Department of Chemistry and Bio- chemistry, San Francisco State University, San Francisco, CA, USA.}

\section{Acknowledgements}

We thank Dr. lan Crandall, University of Toronto, ON, Canada for providing P. berghei ANKA strain. We thank MR4 for providing us with malaria parasite contributed by Dr. Dennis Kyle and Dr. Didier Menard. We also thank Dr. Dea Shahinas for technical support in in vitro and animal studies.

\section{Competing interests}

The authors declare that they have no competing interests.

\section{Availability of data}

All data are presented in the manuscript.

\section{Ethics approval}

The experimental protocol for the mice study (AC13-0119) was reviewed and approved by the Health Sciences Animal Care Committee (HSACC), The University of Calgary, Calgary, Canada. The experiments were done in accordance with the principles by The Canadian Council on Animal Care.

\section{Funding}

The study was supported by a grant from Grand Challenges Canada to DRP (Grant number S4 0226-01).

Received: 2 August 2016 Accepted: 18 November 2016

Published online: 01 December 2016 


\section{References}

1. WHO. World malaria report 2015. Geneva: World Health Organization; 2015. http://www.who.int/malaria/publications/world-malariareport-2015/report/en/. Accessed Dec 2015.

2. Karunajeewa HA, Mueller I, Senn M, Lin E, Law I, Gomorrai PS, et al. A trial of combination antimalarial therapies in children from Papua New Guinea. N Engl J Med. 2008;359:2545-57.

3. Leang R, Barrette A, Bouth DM, Menard D, Abdur R, Duong S, et al. Efficacy of dihydroartemisinin-piperaquine for treatment of uncomplicated Plasmodium falciparum and Plasmodium vivax in Cambodia, 2008-2010. Antimicrob Agents Chemother. 2013:57:818-26.

4. Rogers WO, Sem R, Tero T, Chim P, Lim P, Muth S, et al. Failure of artesunate-mefloquine combination therapy for uncomplicated Plasmodium falciparum malaria in southern Cambodia. Malar J. 2009;8:10.

5. Neckers L, Tatu U. Molecular chaperones in pathogen virulence: emerging new targets for therapy. Cell Host Microbe. 2008;4:519-27.

6. Hemmingsen SM, Woolford C, van der Vies SM, Tilly K, Dennis DT, Georgopoulos CP, et al. Homologous plant and bacterial proteins chaperone oligomeric protein assembly. Nature. 1988;333:330-4

7. Scheibel T, Buchner J. The Hsp90 complex-a super-chaperone machine as a novel drug target. Biochem Pharmacol. 1998;56:675-82.

8. Bonnefoy S, Attal G, Langsley G, Tekaia F, Mercereau-Puijalon O. Molecular characterization of the heat shock protein 90 gene of the human malaria parasite Plasmodium falciparum. Mol Biochem Parasitol. 1994;67:157-70.

9. Acharya P, Kumar R, Tatu U. Chaperoning a cellular upheaval in malaria: heat shock proteins in Plasmodium falciparum. Mol Biochem Parasitol. 2007;153:85-94

10. Wiesgigl M, Clos J. Heat shock protein 90 homeostasis controls stage differentiation in Leishmania donovani. Mol Biol Cell. 2001;12:3307-16.

11. Su XZ, Wellems TE. Sequence, transcript characterization and polymorphisms of a Plasmodium falciparum gene belonging to the heat-shock protein (HSP) 90 family. Gene. 1994;151:225-30.

12. Bracher A, Hartl FU. Hsp90 structure: when two ends meet. Nat Struct Mo Biol. 2006;13:478-80.

13. Csermely P, Schnaider T, Soti C, Prohaszka Z, Nardai G. The 90-kDa molecular chaperone family: structure, function, and clinical applications. A comprehensive review. Pharmacol Ther. 1998;79:129-68.

14. Shonhai A. Plasmodial heat shock proteins: targets for chemotherapy. FEMS Immunol Med Microbiol. 2010;58:61-74.

15. Debnath A, Shahinas D, Bryant C, Hirata K, Miyamoto Y, Hwang G, et al. Hsp90 inhibitors as new leads to target parasitic diarrheal diseases. Antimicrob Agents Chemother. 2014;58:4138-44.

16. Corbett KD, Berger JM. Structure of the ATP-binding domain of Plasmodium falciparum Hsp90. Proteins. 2010;78:2738-44.

17. Shahinas D, Liang M, Datti A, Pillai DR. A repurposing strategy identifies novel synergistic inhibitors of Plasmodium falciparum heat shock protein 90. J Med Chem. 2010;53:3552-7.

18. Borkovich KA, Farrelly FW, Finkelstein DB, Taulien J, Lindquist S. hsp82 is an essential protein that is required in higher concentrations for growth of cells at higher temperatures. Mol Cell Biol. 1989;9:3919-30.

19. Picard D. Heat-shock protein 90 , a chaperone for folding and regulation. Cell Mol Life Sci. 2002;59:1640-8.

20. Voss AK, Thomas T, Gruss P. Mice lacking HSP90beta fail to develop a placental labyrinth. Development. 2000;127:1-11.

21. Shahinas D, Folefoc A, Taldone T, Chiosis G, Crandall I, Pillai DR. A purine analog synergizes with chloroquine (CQ) by targeting Plasmodium falciparum Hsp90 (PfHsp90). PLoS ONE. 2013:8:e75446.

22. Taldone T, Gozman A, Maharaj R, Chiosis G. Targeting Hsp90: smallmolecule inhibitors and their clinical development. Curr Opin Pharmacol. 2008;8:370-4.

23. Mout $R$, Xu ZD, Wolf AK, Jo Davisson V, Jarori GK. Anti-malarial activity of geldanamycin derivatives in mice infected with Plasmodium yoelii. Malar J. 2012;11:54.

24. Pallavi R, Roy N, Nageshan RK, Talukdar P, Pavithra SR, Reddy R, et al. Heat shock protein 90 as a drug target against protozoan infections: biochemical characterization of HSP90 from Plasmodium falciparum and Trypanosoma evansi and evaluation of its inhibitor as a candidate drug. J Biol Chem. 2010;285:37964-75.

25. Jhaveri K, Modi S. HSP90 inhibitors for cancer therapy and overcoming drug resistance. Adv Pharmacol. 2012;65:471-517.
26. Shahinas D, Macmullin G, Benedict C, Crandall I, Pillai DR. Harmine is a potent antimalarial targeting $\mathrm{Hsp} 90$ and synergizes with chloroquine and artemisinin. Antimicrob Agents Chemother. 2012;56:4207-13.

27. Eagon S, Anderson MO. Microwave-assisted synthesis of tetrahydro$\beta$-carbolines and $\beta$-carbolines: microwave-assisted synthesis of $\beta$-carbolines and congeners. Eur J Org Chem. 2014;2014:1653-65.

28. Wassenberg JJ, Reed RC, Nicchitta CV. Ligand interactions in the adenosine nucleotide-binding domain of the Hsp90 chaperone, GRP94. II. Ligand-mediated activation of GRP94 molecular chaperone and peptide binding activity. J Biol Chem. 2000;275:22806-14.

29. Takashi R, Tonomura Y, Morales MF. 4,4'-Bis (1-anilinonaphthalene 8-sulfonate) (bis-ANS): a new probe of the active site of myosin. Proc Natl Acad Sci USA. 1977;74:2334-8.

30. Noedl H, Attlmayr B, Wernsdorfer WH, Kollaritsch H, Miller RS. A histidinerich protein 2-based malaria drug sensitivity assay for field use. Am J Trop Med Hyg. 2004;71:711-4

31. Noedl H, Bronnert J, Yingyuen K, Attlmayr B, Kollaritsch H, Fukuda M. Simple histidine-rich protein 2 double-site sandwich enzyme-linked immunosorbent assay for use in malaria drug sensitivity testing. Antimicrob Agents Chemother. 2005:49:3575-7.

32. WWARN. P. falciparum ex vivo drug sensitivity based on HRP2 ELISA WWARN procedure. 2011.

33. Bayih AG, Pillai DR. Mouse studies on inhibitors of Plasmodium falciparum Hsp90: progress and challenges. Parasitology. 2014;141:1216-22.

34. Soares RR, da Silva JMF, Carlos BC, da Fonseca CC, de Souza LSA, Lopes $\mathrm{FV}$, et al. New quinoline derivatives demonstrate a promising antimalarial activity against Plasmodium falciparum in vitro and Plasmodium berghei in vivo. Bioorg Med Chem Lett. 2015;25:2308-13.

35. Liang J, Li Y, Liu X, Huang Y, Shen Y, Wang J, et al. In vivo and in vitro antimalarial activity of bergenin. Biomed Rep. 2014;2:260-4.

36. N'Da DD, Lombard MC, Clark JA, Connelly MC, Matheny AL, Sigal $M$, et al. Antiplasmodial activity and cytotoxicity of 10ß-aminoquinolinylethylethers of artemisinin. Drug Res. 2013:63:104-8.

37. Ramirez-Mares MV, Chandra S, de Mejia EG. In vitro chemopreventive activity of Camellia sinensis, Ilex paraguariensis and Ardisia compressa tea extracts and selected polyphenols. Mutat Res. 2004;554:53-65.

38. Cowen LE. The fungal Achilles' heel: targeting Hsp90 to cripple fungal pathogens. Curr Opin Microbiol. 2013;16:377-84

39. Shahinas D, Folefoc A, Pillai DR. Targeting Plasmodium falciparum Hsp90: towards reversing antimalarial resistance. Pathogens. 2013;2:33-54.

40. Taldone T, Sun W, Chiosis G. Discovery and development of heat shock protein 90 inhibitors. Bioorg Med Chem. 2009;17:2225-35.

41. Meyer KJ, Shapiro TA. Potent antitrypanosomal activities of heat shock protein 90 inhibitors in vitro and in vivo. J Infect Dis. 2013;208:489-99.

42. Porter JR, Fritz CC, Depew KM. Discovery and development of Hsp90 inhibitors: a promising pathway for cancer therapy. Curr Opin Chem Biol. 2010;14:412-20.

43. Roe SM, Prodromou C, O'Brien R, Ladbury JE, Piper PW, Pearl LH. Structura basis for inhibition of the Hsp90 molecular chaperone by the antitumor antibiotics radicicol and geldanamycin. J Med Chem. 1999;42:260-6.

\section{Submit your next manuscript to BioMed Central and we will help you at every step:}

- We accept pre-submission inquiries

- Our selector tool helps you to find the most relevant journal

- We provide round the clock customer support

- Convenient online submission

- Thorough peer review

- Inclusion in PubMed and all major indexing services

- Maximum visibility for your research

Submit your manuscript at www.biomedcentral com/submit 